\title{
METHODOLOGIC ELEMENTS NECESSARY IN MAKING FORECASTS FOR REGIONAL
}

Țimerman Dumitru, Ec.

NORTH-WEST TV SATU MARE

Deju Mihai, Professor, PhD

UNIVERSITY OF BACĂU

\begin{abstract}
Regional picture appear two Romanians: a richer, which includes the Bucharest-Ilfov, West and Center and a poor, other regions. Among the most competitive districts are Ilfov (8. 553 euro per capita), Timiş (7. 931 euro per capita), Braşov (7. 108 euro per capita), Arad (6. 675 euro per capita), Cluj (6. 561 euro per capita), Constanta (6. 368 euro per capita), and among the poorest Botosani (2. 745 euro per capita) and Vaslui (2.930 euro per capita).

According to a report by the National Prognosis Commission (CNP), while Bucharest-Ilfov region will have a GDP per capita of 11.694 euros next year, the Northeast will remain poverty pole, 3. 826 euro per capita.

Economists argue that, if not reduce disparities, mainly through public investment, we could assist in disruption of important social and economic environment. Lowering differences would include the maintenance of close growth rates of GDP / capita, and these important gaps.

Economic analysts draw attention to the dangers which may arise due to different levels of development. Develop forecasts in territorial - at regional or county-is a necessary and useful approach in the perspective of Romania in the European Union. From this point of the assessment of regional economic disparities and the potential development of each area provides an important support kinesiology orientation and use with maximum efficiency of the structural funds and cohesion funds that Romania will benefit by integrating.

Regional forecasts provide information on possible future development, with employment in the global data of the national economy as a whole.
\end{abstract}

\section{Methods of regional forecasting}

Because each zone is treated separately in the context of development throughout the country, regional forecast is more than a breakdown by region of some macroeconomic indicators.

Analyzed to predict the level of each region, can highlight their contribution to the overall development of the Romanian economy, and how the programs of regional development are reflected in the future development of the regional economy, this ensuring a better economic foundation of prognoses nationally.

How important is that the regional forecasts are ascending method (in which it is based on information relative units in a region and to obtain the sum total regional); descending method (which distributes a number of different national regions with the help of key distribution) and mixed methods (combining methods upward and downward, depending on the data available and reliable in the region).

Each of the methods summarized above have advantages and disadvantages of its. Benefits could be a direct call to the relevant data sources at regional level for ascending method, numerical or guarantee coherence between national and regional for the second, which would have the disadvantage of not providing estimates are calculated starting of direct data, but through a key distribution to be correlated with the phenomenon analyzed.

Basically, the regional development prognoses were combined methods mentioned, especially that from the database statistics, there are two major impediments, namely: lack of data on the evolution of territorial price, making the assessment and forecast growth regions have a greater degree of relativity, and that the regional statistics 
has a delay of 1-2 years from the national, which includes the estimates for past periods.

In conclusion, forecast at the regional level reveals differences between regions in the context of development throughout the country, differences that tend, since 2005 , to be diminishing, achieving a balance in the evolution trends of the indicators analyzed in the regions.

It may emphasize, first, the need for a reduction of differences in the evolution of the industrial sector, by broadening the mixed or private capital in areas with predominantly state capital, thus avoiding liquidation or restructuring of enterprises, which would lead to lower economic activity in those areas. Also be exploited tourism potential of each region in order to balance the other shortcomings of the economic zone. Attracting foreign investment is another important factor in reducing disparities, including unemployment in certain areas of the country with a poor development or May with a predominance of rural activities (such as the North - east or the south ).

\section{Existing disparities between the years 2005-2008}

The statistics show that Romania has entered the transition with a relatively low level of regional disparities, compared with other Member States or candidate countries. They have grown rapidly and in particular between Bucharest and the rest of the country.

In the year 2005, there were gaps in the regions where most agricultural counties coexist with the most developed. This phenomenon has been widespread due to the impact of economic restructuring in particular areas monoindustriale, whose population has been affected by unemployment due to closure of unprofitable state enterprises.So, we can mention the border with Moldova and Ukraine and less-developed over the Danube.

Evolution industrial ${ }^{1}$ production indices at counties and regions in 2005

\footnotetext{
${ }^{1}$ Indices of industrial production (IPI) characterize the evolution of total industrial production at the county level, IPI while calculated to characterize the evolution of national gross value added at factor cost, carried out in industrial activity. They were calculated in each county based on data from the "Statistical Research on
}

compared to 2004, leads to the following conclusions:

- The industrial production indices counties recorded in 2005, contradictory values, from $-20.2 \%$ in Suceava ( North East) to $37.5 \%$ in Teleorman County (South Region)

- Industrial developments were diametrically opposed and regions:

- In Region North - East, was the largest gap between the maximum and minimum of industrial production, about 35 percent. Thus, Bacau which has the greatest contribution to the regional industrial production achieved in 2005, the biggest jump of $15.3 \%$, mainly on account of manufacturing industry, with an increase of $19.4 \%$. On the opposite side was Suceava to $20.2 \%$;

- And in the South Region - East have been discrepancies between counties, but the spread was less, about 15 percent. Buzău County was one that experienced the greatest increase, $4.3 \%$ and the lowest level was in the county of Tulcea, $-12.2 \%$, one of the lowest in the country;

- In the South Region, was the biggest leap of industrial Teleorman County $37.5 \%$, but it has a relatively small contribution in the regional industrial output compared with Prahova County giving over $30 \%$ of it, and whose industry has exceeded in 2005 to $9.9 \%$ in 2004. Calarasi county was made at the lowest level $(-3.9 \%)$ in the region;

- As regards the South Region - West differences were about 10 percent, from $13.7 \%$ in Olt county, at $-6.1 \%$ in Mehedinti county

- the Western Region, except in CarasSeverin county $(-1.1 \%)$, three counties have achieved growth, the highest level recorded in Arad (16.8\%)

- in the North Region - West emerges Bistrita-Nasaud county with $15.3 \%$ at the stand opposed to $-8.7 \%$ in Cluj, who gives more than $30 \%$ of industrial production in the region

- The center has achieved the highest in the county of Alba (14.2\%) and lowest in Covasna (-4.8\%)

physical industrial production (IND) in 2004 and the" short-term indicators in industry (INDTS) in 2005. 
- In Region Bucharest developments were close, $3.4 \%$ in Ilfov county and $3.2 \%$ in Bucharest;

- Developments in industrial districts and with different weights that each county contribute to industrial production in the region which forms part, as did industrial production to be above the national average, which was $2 \%$ in the following regions: East, West, Bucharest and South - West. Center region was at the national level. Under achieved on the total economy were the North - West, North - East and South - Eastern Europe, whose industrial production fell.

Besides Bucharest, which is specific growth followed a west-east direction, proximity to western markets, acting as a distribution of growth. Although statistical data shows some variation over time due to local factors, it can be seen as economic growth had a significant geographical component, underdeveloped areas are concentrated in the North - Eastern border with Moldova and the South, along the Danube. Under-appears to be strictly correlated with unemployment and the prevalence of rural activities, and inability to attract foreign direct investment. Western Areas and the center of the country were advantaged by their position closer to Western markets and lower their dependence of the primary sector. Until now, they have received more foreign direct investment.

Different causes of disparities in economic and social development at the intraregional as future developments are to be quite unpredictable.

In terms of economic growth in the year 2005, the total economy, it has been a slow $(4.1 \%)$ compared to previous years, the decline in agricultural production due to rain and floods that have affected Romania more times in spring and summer of last year and a slower increase $(2 \%)$ of industrial production. Level region, the increases were different from $2.2 \%$ in Northern Region - East to $7.3 \%$ in Bucharest Region.

Regional developments in 2005 were marked by flagging agricultural production, especially in areas with a strong profile of agriculture, but also supported the pace of construction works, as the areas affected by weather vagaries were needed extensive work reconstruction of infrastructure (roads, bridges, railway embankments, etc.. ) And the restoration of housing space, in areas damaged by rain and flooding.

At the national level, economic growth has been supported in principle the construction $(9.9 \%)$ and services $(8.1 \%)$, industries with a more modest contribution $(2.5 \%)$, while the agricultural sector recorded a decrease of 13.9 percent.

A detailed analysis based on figures from each region and nationally, show that for 2005 , an average growth over the economy (4.1\% compared to 2004 ) have achieved only regions Bucharest (7 3\%) and West (5.6\%), increase of the latter being supported by industry, with a gross value added of $6.5 \%$ and services $10 \%$. Other regions were below the national average, being the closest center (3.8\%) and South $(3,7 \%)$. The South has made in 2005, the biggest jump of the gross industrial value added ( $8 \%)$, but increased intake of it was largely wiped out by the reduction in agricultural production following the devastating effects they have had floods last summer on crops, this area is an agricultural area with extensive. The South East South - West and North - West achieved an increase of $2.6 \%$. The lowest level was recorded in the North - East, 2.2\%, mainly due to a reduction of gross value added in industry $(-1.4 \%)$ and agriculture $(-15 \%)$.

In industry there have been various developments in one region to another, where the average national gross value added of this industry was $2.5 \%$, have been spectacular developments in the region (South of $8 \%$, with 6.5 Western \%), with some modest developments (Bucharest by 3.5\%, South West to $2.3 \%$ and center $2 \%$ ), while others showed a decline (North - East with -1.4\% and North - West 1.8\%).

In all regions, agriculture has been strongly affected by weather conditions, the gross added value is reduced by more than 10 percent.

In construction, developments were between $8.8 \%$ in the center and $10.6 \%$ in the Bucharest.

Within the services of noted West region with $10 \%$ followed by North - East 
with 9.5\% and North - East 9\%. The lowest was in South Region (6.5\%).

Analysis of the evolution of foreign trade in each region show, also significant differences. It is noteworthy that most of the Romanian foreign trade is done through the Bucharest region, which in 2005 represented about $21 \%$ of total exports of goods and about $40 \%$ of total imports, the trade deficit represents about $78 \%$ of total country. Other regions share in total country between $6.3 \%$ (South Region - West) and 15.7\% (Western Region) for the export of goods. Imports of goods, contributions ranged from $2.6 \%$ (South Region - West) and 11.5\% (The Center).

As regards developments in the dynamics of foreign trade in 2005 , the total country exports increased by $17.5 \%$ while imports were $23.9 \%$ compared to 2004 . Region at the most significant growth in both imports $(67.9 \%)$ and export $(58.4 \%)$ was achieved in the South Region. Increases above the national average exports have made the North - East (19.5\%) and South - West (23.9\%), while imports only center region with $24.1 \%$. As a result, there were trade deficits in almost all regions, Region Bucharest, being in first place in this regard. I noted areas where there has been a surplus of trade balance, and South - East and West.

$$
\text { Although reducing economic }
$$
disparities is a long term process, whether it is about differences between countries or regions of the same countries, however, prospects for real reduction can be identified in the evolution of the medium-term phenomenon.

Under these conditions, the evolution in recent years and prospects through 2008 shows that at this time we talk about maintaining an economic gap between regions. The ratio of maximum (West region) and minimum (North - East) of the gross domestic product per capita in the euro remains constant at about 1.7 (compared to the excluded region that Bucharest has a GDP per capita very high). That gap is not deep, especially in view of attracting the positive effects of structural funds, creates preconditions for reducing the gap after 2008.
3 Share of sectors in total employment

Region Bucharest is the only region of the country in which services, which nationally have $38 \%$ of total employment, generating the most important jobs, reaching $63.4 \%$ of total employment in the region. Construction industry and hold $30 \%$ of total employment, regions beyond this level were center (35\%), West (34.7\%), Bucharest (31.9\%) and North - West (30.3\%). Average national level has been exceeded and the West and Center with a share of the population in the occupied area of $41.8 \%$ respectively $38.6 \%$. Region Bucharest is the only region of the country in which services, which nationally have $38 \%$ of total employment, generating the most important jobs, reaching $63.4 \%$ of total employment in the region. In 2005 only 2 areas had earnings above the national average (Bucharest: with 23.4\% and South - West: 0.3\%). Average national level has been exceeded and the West and Center with a share of the population in the occupied area of $41.8 \%$ respectively $38.6 \%$. In respect of the South - West is notable that the Gorj County raises wages above average and this area due to mining on its territory. In 2005 only 2 areas had earnings above the national average (Bucharest: with 23.4\% and South West: $0.3 \%$ ). Earnings significantly below the national average were recorded in the North East (with $10.3 \%$ being the lowest earnings), center (with 8.2\%) and North - West (to $6.5 \%$ ). In respect of the South - West is notable that the Gorj County raises wages above average and this area due to mining on its territory. Earnings significantly below the national average were recorded in the North East (with $10.3 \%$ being the lowest earnings), center (with 8.2\%) and North - West (to $6.5 \%)$.

Disparities between regions were reduced from $42.1 \%$ in 2000 to $33.7 \%$ in 2005. The gap is still significant due to higher earnings achieved in the Bucharest.

Regional disparities of income is supplemented by maintenance discrepancies in terms of unemployment, even if it has known in recent years a significant reduction.

The highest level of unemployment in 2005 was recorded in the North - East South East, South, South - West and Center with 
unemployment rates above the national average $(5.9 \%)$ and lowest level was registered in the Bucharest (2.8\%).

If at the national level for civilian employed population at the end of growth was $0.1 \%$, at the regions, except Bucharest (3.3\%) and West region $(0.7 \%)$, this area is the favoured position closer to Western markets for the other regions the values are slightly decreased compared to the previous year, some of these regions is dependent on agriculture and affected by proximity to the border with Moldova and Ukraine (in the case of the North - East) or reducing cross-border trade due Danube (in the case of the South).

Average number of employees registered increases above the national average (2.9\%) in Bucharest (7.0\%) and West $(3.0 \%)$ and increases under the national average in all other regions. Evolution of earnings in 2005 indicates an increase from the previous year with $22.1 \%$ nationally, stand is on a downward trend, even in conditions arising from the introduction of flat income tax wage.

Real wage growth (calculated as the ratio between the index of average net earnings and the consumer price index) was $12.1 \%$ nationally, with considerable increases over the national average in four regions (West, North - West, Center and Bucharest ) and the national average in the other four regions (North - East South - East, South and South - West). What is noteworthy is that these increases are generally less than $+/-1$ percentage point compared to the national average. Romania is the only country in the area that had increases in average gross salary of two digits - $20 \%$ in first five months of 2008 compared to same period of 2007 which, in a pessimistic scenario, inflation could fathom, said, for NewsIn, chief economist of the National Bank of Romania, Valentin Lazea. "We have a pharmaceutical influence the gross average wage growth on inflation, but it is evident that the countries in transition, in the area, but wages in Romania rose by over $20 \%$ from last year. In Central European countries, Hungary, Poland, Slovakia, about eight years wage growth is a single figure and this is reflected in the inflation rate. November sowing, from this point of view, the Baltic countries, where you remember how much inflation has increased after the boom ended. Or Ukraine, where last year there was a wage increase of $40 \%$ and inflation $30 \%$. Not to say that we could arrive at such rates of inflation, but it is clear that you can have an increase of $25 \%$ of wages and inflation of $5 \%$, "said chief economist of the National Bank of Romania, Valentin Lazea. In the first half of 2008, average inflation was $0.6 \%$, twice that of the first six months of 2007, according to statistical data, while wages have climbed to five months, almost one quarter (24 98\%) being under analysts, an important factor of deepening inflation. In the first five months of 2008, Romanians have won, on average, 1. 651.6 lei, 33 lei more than the average interval from 1321.6 lei similar in 2007. Wage increases have put pressure on inflation trends, the average is practically doubling in the first six months of 2008 from January to June 2007, from $0.3 \%$ to $0.6 \%$.

Establish a regional development and reduce economic and social disparities between different regions involving all areas, from the purely economic (creation of SMEs, infrastructure, environment, development of agriculture) to the socio-cultural (unemployment, human resources, education). Regions of Romania are below the average level of economic development of regions in member countries of the Union, but have internal differences and. This situation makes it necessary to adopt a series of measures, supporting growth and improving living conditions by exploiting the potential of effective regional and local initiatives to stimulate, foster domestic interregional cooperation, aimed at reducing regional imbalances and prevent other international imbalances, in order finally to increase the living standards of citizens. However, the policy of regional development in Romania has a tradition formal and documented. In 1990, Romania was a country relatively evenly developed, which were added precipitation budgetary resources of the entire period, as Romania did not feel the need for a formal policy on regional development. Forced industrialization policy carried by the socialist regime had the effect of levelling the 
degree of development of the whole country, although this was achieved by building of industrial facilities that did not have any competitive advantage which in the process of transition the economy have come largely disabled. Regional policy has been incurred solely in response to availability of financial assistance from the European Union. Given the controversy that the idea of regionalization has generated public authorities preferred institutional framework and the establishment of eight development regions, not offering an argument visible in their construction and obvious attempt to avoid historical criterion. Basically, the law does not provide regional development such a criterion, stating only that the development is born by a voluntary association of local authorities. In Chapter II of the law are given the development in accordance with the objectives of economic and social cohesion, for which the European Institute of Romania has conducted impact studies. In regional development work for regional development agencies that are non-governmental bodies, nonprofits, public utility, but with legal. Although Romania has entered the transition with a relatively low level of regional disparities, compared with other Member States or candidate countries, disparities have grown rapidly both at interregional and sub regional.

According to statistics, among the least developed regions are North-East and South America, and the most developed Bucharest and Ilfov County and West. Within regions, disparities remain, and predominantly agricultural country, those marked by unemployment due to restructuring, with little investment and rudimentary infrastructure, those with environmental or urban areas in decline coexist with others that are less affected by these problems. This is the case of the West, where a Timiş county with a GDP more than Hunedoara. In addition, within the counties were declared disadvantaged areas with declining industries (eg mining regions in the county of Gorj, Hunedoara and Suceava).

Geographical level, there are increasing because economic development tends to concentrate in the area of Bucharest, and inequalities in urban areas are growing. Thus the state must intervene with significant financial resources to combat poverty and reduce inequalities, with concrete measures against unjustified and polarization between rich and poor which has widened in Romania. Reducing disparities, the harmonious development involving, primarily, new programs, additional financial resources and new people to implement regional development programs. Regional policy can be judged from the perspective used by the central authorities and local resources available, combinations of tools for economic and financial policy in order to stimulate investment, create jobs and improve living conditions in a region / territory specific. Such instruments of economic policy covers a wide range, from the general nature such as, the legal framework intended to support development of economic regulations specific measures such as state aid granted to firms in order to stimulate investment or projects to support the restructuring.

\section{References}

[1] Report of the National Forecast

[2] Research statistics on industrial production of natural-IND 2004

[3] Short-term indicators in industry - 2005

[4] The regional National Commission of Prognosis

[5] Law 315/2004

[6] National Commission of Prognosis, Institute National Statistics

[7] National Strategic Reference Framework 2007-2012-Summary

[8] No Info economic.14, 11-17 July 2007

[9] Issues of regional development in Romania, Narcisa Mosteanu Roxana, Ed. Sylvia, Bucharest 2001, p.85-94.

[10] Currier National No. 5219 - 25 July 2008. 